\title{
Effectiveness of the new water source intervention in reducing diarrheal diseases in Ghindae community, Eritrea
}

'Abraham Kebedom, 'Tadesse Teclebirhan, 'Prof. Jacob Mufunda and 'Prof. Andemariam Gebremicheal

Institutional affiliation

Orotta School of Medicine, PO Box 10549, Asmara, Eritrea

Correspondence to be sent to akebedom@yahoomail.com

Background: Diarrheal diseases are an important cause of morbidity and mortality in developing countries particularly in children. In Ghindae, a town $45 \mathrm{~km}$ from Asmara the capital city of Eritrea, diarrheal diseases were the commonest disease among all age groups. Based on findings from operational research, the old water supply of the town was believed to be the main source of the disease. A new water supply system was built for the community.

Objective: The objective of this study was to evaluate the effectiveness of the new water supply system intervention in reducing diarrheal diseases in Ghindae community.

Methods: Retrospective study was done base on the records of the Hospital.

Results: The incidence of diarrhea decreased by $15 \%$ after the introduction of a new water distribution system. The decrease was $44 \%$ for giardiasis and $25 \%$ for amoebiasis. There was no change in the bloody diarrhea disease burden.

Conclusion: The incidence of diarrhea was still unacceptably high in spite of the revamping of the water system, an observation which calls upon other contributory factors such as point use contamination and socio-economic status.

\section{Introduction}

Diarrheal diseases are the major cause of morbidity and mortality among children in many developing countries, particularly in sub-Saharan Africa ${ }^{1}$. One of the contributory factors predisposing children to diarrhea is the water and sanitation contamination vicious cycle ${ }^{2}$. In Eritrea, diarrhoeal disease is one of the most frequent causes of illness and a major contributor to mortality among children. A report based on data from health management system in Eritrea clearly demonstrated that diarrhea was a major public health problem which needed attention ${ }^{3}$.

There are many factors that contribute to diarrheal diseases but water contributes most. If minimum standards for water safety are not maintained from its source to the level of consumption, it could be a source of wide spread diseases, manifested by gastrointestinal symptoms mainly diarrhea. Some of these diarrheal diseases are ameobiasis, gardiasis, bloody diarrhea, shigellosis, salmonellosis, hepatitis $A$, and rotavirus. These diarrheal diseases are very common in the Ghindae community ${ }^{4}$, small town with a population of 20,000 people, located on the main road of Eritrea's capital city Asmara and port city Massawa.

Diarrheal diseases such as ameobiasis and gardiasis constitute third and fourth among the top ten burden diseases of Ghindea hospital in 2006 and 2007.,5 According to the information from Ghindae, the diarrheal diseases were so common between 2000 and 2003. In 2003 an investigation was done by the Human Resource Development of the $\mathrm{MOH}$ State of Eritrea reproved that the water was heavily contaminated. During that time the source of water was a dam (surface water).
In 2004, a new underground source of water was built and was in use during the time of the study. The old water distribution system was completely replaced. The water was pumped from ${ }^{4}$ drills found in the bed of Mai Adkemom (local river), to a reservoir from where a new pipe system collected and delivered the water for human consumption. ${ }^{5}$

Despite the improvement in the source of water of the town diarrheal diseases such as ameobiasis gardiasis and bloody diarrhea appear to be common health problems in the community among the first five top ten burden diseases in Ghindea hospital in 2007. ${ }^{4}$

The objective of this study was to evaluate the effectiveness of the new water supply system intervention and related factors in reducing diarrheal diseases in the community and to determine the trend in the prevalence of diarrheal diseases in Ghindea hospital.

\section{Methods and materials used}

A retrospective study was done on the data available in the sub-zoba. Data was collected from the statistical office related to the diarrheal diseases since 2000-2007. All the data was on the record of the hospital, they keep recording all the prevalent diseases in the sub-zoba.

\section{Results}

Medical records of all children with diarrhoeal diseases between 2000 and 2008 were retrieved. The overall number children with all formas of diarrhea fluctuated during the period of study with the highest in 2000 followed by 2004 and 2003 but tended to decrease from 2005 until 2007. The cases 
with bllody diaarhea were highest in 2003 and 2004 and then decreased to remain contant at a lower level thereafter. Both cases from from amoebiasis and giardiasis significantly decreased afer 2004. Cases of diarrhea without dehydration increased after 2004 and continued to fluctuate at higher levels. The trend for diarrhea with dehydration was non specific with no defined pattern (Table 1).

Table 1: Annual trends of incidence of diarrheal disease in Ghindae Hospital

\begin{tabular}{|l|c|c|c|c|c|c|c|c|}
\hline Year & 2000 & 2001 & 2002 & 2003 & 2004 & 2005 & 2006 & 2007 \\
\hline $\begin{array}{l}\text { All forms of } \\
\text { diarrhea }\end{array}$ & 3250 & 2617 & 2795 & 3031 & 3053 & 2509 & 2432 & 2551 \\
\hline $\begin{array}{l}\text { Bloody } \\
\text { diarrhea }\end{array}$ & 17 & 9 & 61 & 132 & 252 & 117 & 52 & 92 \\
\hline Ameobiasis & 1113 & 1024 & 1357 & 1355 & 973 & 809 & 870 & 917 \\
\hline Gardiasis & 1304 & 1029 & 880 & 796 & 609 & 510 & 539 & 490 \\
\hline $\begin{array}{l}\text { Diarrhea } \\
\text { with } \\
\text { dehydration }\end{array}$ & 782 & 271 & 437 & 599 & 388 & 278 & 462 & 282 \\
\hline $\begin{array}{l}\text { Diarrhea } \\
\text { with out } \\
\text { dehydration }\end{array}$ & - & - & 40 & 129 & 822 & 724 & 483 & 622 \\
\hline
\end{tabular}

The number of cases was analysed with reference to the timing of the introduction of the new water systems. When the data was disaggregated according to causative agent, it was found that all forms of diarrheal diseases decreased by $15 \%$. Amoebiasis decreased by $25 \%$ whereas giardiasis decreased by $44 \%$ with bloody diarrhea remaining essentially unchanged (Table 2).

Table 2: Trends of selected diarhhoea diseases before/after new water system

\begin{tabular}{|l|l|l|l|l|l|l|l|l|}
\hline \multirow{2}{*}{$\begin{array}{l}\text { Per } \\
\text { iod }\end{array}$} & \multicolumn{2}{|l|}{$\begin{array}{l}\text { All forms of } \\
\text { diarrhea }\end{array}$} & \multicolumn{2}{l|}{$\begin{array}{l}\text { Bloody } \\
\text { diarrhea }\end{array}$} & \multicolumn{2}{l|}{ Amoebiasis } & \multicolumn{2}{l|}{ Giardiasis } \\
\cline { 2 - 9 } & $\begin{array}{l}\text { Total } \\
\text { Ann } \\
\text { ual } \\
\text { Mean }\end{array}$ & $\begin{array}{l}\text { Total } \\
\begin{array}{l}2000- \\
2004\end{array}\end{array}$ & $\begin{array}{l}\text { Ann } \\
\text { ual } \\
\text { Mean }\end{array}$ & Total & $\begin{array}{l}\text { Ann } \\
\text { ual } \\
\text { Mean }\end{array}$ & $\begin{array}{l}\text { Total } \\
\begin{array}{l}\text { Ann } \\
\text { ual } \\
\text { Mean }\end{array}\end{array}$ \\
\hline $\begin{array}{l}2005- \\
2007\end{array}$ & 7492 & $\begin{array}{c}2500 \\
(15 \%)\end{array}$ & 261 & $\begin{array}{c}87 \\
(7 \%)\end{array}$ & 2596 & $\begin{array}{c}865 \\
(25 \%)\end{array}$ & 1539 & $\begin{array}{c}513 \\
(44 \%)\end{array}$ \\
\hline & & & & & & & & \\
\hline
\end{tabular}

Figure 1: Trends of selected diarhhoea diseases before/ after new water system

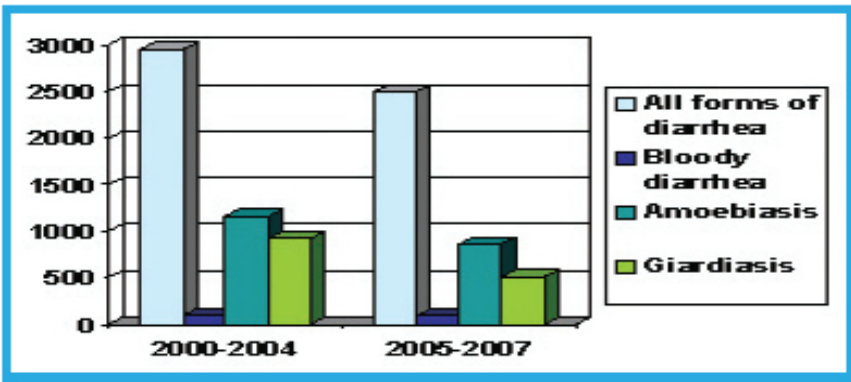

In 2007, after the introduction of the new water system, diarrhea with out dehydration, ameobiasis and gardiasis were respectively ranked $2^{\text {nd }}, 4^{\text {th }}$ and $6^{\text {th }}$ most prevalent diseases among the children under 5 years of age presenting to the OPD in Ghindae hospital. The ranking for children older than 5 years of age was the same except giardiasis which was ranked $5^{\text {th }}$ instead of $6^{\text {th }}$. Among inpatients, amoebiasis was ranked $3^{\text {rd }}$ for all age groups.

\section{Discussion}

This study was done to evaluate the effectiveness of the new water supply system in reducing the diarrheal disease in Ghindae. After the introduction of a new water distribution system, the incidence of diarrheal diseases decreased by $15 \%$. The decrease was $44 \%$ for giardiasis and $25 \%$ for amoebiasis. There was no change in the bloody diarrhea disease burden.

The etiological agents of diarrhea in the setting of Ghindae are different from reports from other studies where diarrhegenic Escherichia Coli has dominated among the cases. In addition rotavirus has played an important role in the diarrhea disease burden in other studies ${ }^{7}$. The different socioeconomic status of communities and environmental factors may provide some explanations for the different diversity of etiological agents for diarrhea in Eritrea ${ }^{8}$.

This study showed that the new water system have contributed to the reduction of the diarrheal diseases but it was not that much significant to say that confidently that the old water supply system was the sole source of the diarrheal diseases. Metanalytical studies on eltiology of diarrheal diseases have incriminated point use contamination as a realistic factor in transmission of diarrhea in some settings ${ }^{2,6}$. The persistence of diarrhea may be an indicator of need for point of use chemical treatment of water for human consumption.

Safe water is one of essential components or needs for healthy living, along with adequate sanitation and proper nutrition ${ }^{9}$. Since 2000 all, these forms of diarrheal diseases were increasing until 2004. From 2004 these diseases were decreasing a lit bit but not to the level of expected in reduction of the diarrheal diseases, because it was believed that the old contaminated source of water was the main cause. One possible explanation for the minimal change in the prevalence of these diarrheal diseases is that the water source Mai Adkemom (the local river) crosses through the town and is used frequently for drinking purposes when there is shortage of the main source of water. More over the tax for the truck water is high (7-9) nacfa per Barrel, and 50 cents for a 20-liter gallon of water and some families prefer to bring water from that river and other wells due to their poor economical situation. ${ }^{5}$

It was also a usual habit for the small children to wash, swim and drink from that river. The fact that these diseases were not only transmitted through water could explain partly as the river was used for garden purposes and ameobiasis and gardiasis can be spread through improperly washed and undercooked 
green vegetables. However, the effect of these gardens of green vegetables was minimal, as it did not contribute much to the markets of Ghindea. This study also showed that environmental and socioeconomic factors are also very important determinants in causing diarrheal disease.

\section{Conclusion}

The trends of diarrheal diseases generally were increasing until 2004 and it were decreasing but not to the minimal level. The intervention was found to effective but not as much as expected. Diarrheal diseases remain common health problems in the Ghindea community. From this study, it can be concluded that it is necessary to study and investigate the different sources of water for their safety and look for other source of contamination and it is necessary to study the environmental and socioeconomic factors of the community.

\section{Reference:}

1. Prüss A, Kay D, Fewtrell L, Bartram J.Estimating the burden of disease from water, sanitation, and hygiene at a global level. Environ Health Perspect. 2002;110(5):537-42.

2. Banda K, Sarkar R, Gopal S, Govindarajan J, Harijan BB, Jeyakumar MB, Mitta P, Sadanala ME, Selwyn T, Suresh
CR, Thomas VA, Devadason P, Kumar R, Selvapandian D, Kang G, Balraj V. Water handling, sanitation and defecation practices in rural southern India: a knowledge, attitudes and practices study.Trans R Soc Trop Med Hyg. 2007 Nov;101(11):1124-30. Epub 2007 Aug 31

3. Mufunda J, Nyarango P, Kosia A, Ogbamariam A, Mebrahtu G, Usman A, Gebresillosie S, Goitom S, Araya E, Andemichael G, Gebremichael A. Continuing communicable disease burden in Eritrea. S Afr Med J. 2006; 96(3):221-4.

4. Ghindae Hospital, Eritrea, HMIS and IDSR reports 20002007.

5. Ghindae town, Eritrea, Administrative reports 2006.

6. Fewtrell L, Kaufmann RB, Kay D, Enanoria W, Haller L, Colford JM Jr. Water, sanitation, and hygiene interventions to reduce diarrhoea in less developed countries: a systematic review and meta-analysis. Lancet Infect Dis. 2005;5(1):4252.

7. Mandomando IM, Macete EV, Ruiz J, Sanz S, Abacassamo F, Vallès X, Sacarlal J, Navia MM, Vila J, Alonso PL, Gascon $J$. Etiology of diarrhea in children younger than five years of age admitted in rural hospital of southern Mozambique. Am JTrop Me Hyg 2007;76:522-7.

8. Woldemichael G. Diarrheal morbidity among children in Eritrea. J Health Popul Nutr 2001; 19:83-90.

9. Sobsey MD, Bartram S.Water quality and health in the new millennium: the role of the World Health Organization Guidelines for Drinking-Water Quality. Forum Nutr. 2003;56:396-40. 